\title{
CARACTERIZAÇÃO BIOQUÍMICA DE LEVEDURAS ISOLADAS DE BAGAÇO E PALHA DE CANA-DE-AÇÚCAR
}

\author{
L. M. MILANI ${ }^{1 *}$, V. TADIOTO $^{1}$, M. FILIPPINI ${ }^{1}$, E. T. BARRILLI ${ }^{1}$, \\ S. L. ALVES JR ${ }^{1}$
}

${ }^{1}$ Engenharia Ambiental e Sanitária, Campus Chapecó, Universidade Federal da Fronteira Sul

*E-mail para contato: leticiamilani3@gmail.com

\begin{abstract}
RESUMO - A produção nacional de etanol é majoritariamente oriunda da fermentação do caldo de cana-de-açúcar e do melaço, substratos ricos em sacarose. A partir dessa produção obtêm-se anualmente cerca de 150 milhões de toneladas de bagaço de cana, algo que também pode ser utilizado na produção de etanol, nesse caso de segunda geração, devido ao alto teor de carboidratos presentes nessa biomassa lignocelulósica. A levedura mais bem adaptada ao processo de fermentação em indústrias sucroalcooleiras é a Saccharomyces cerevisiae. Entretanto, S. cerevisiae é incapaz de fermentar uma boa parte dos carboidratos existentes nesses resíduos. Assim, com o objetivo de selecionar espécies que possam contribuir para a viabilização da produção de etanol de segunda geração, o presente trabalho se propôs a analisar o metabolismo de leveduras isoladas de bagaço e palha de cana-de-açúcar. Das 16 linhagens isoladas, 4 foram testadas em meios mínimos contendo alternadamente glicose, xilose ou celobiose como fontes de carbono. As cepas analisadas consumiram todos os carboidratos durante o tempo de incubação. Contudo, embora o rendimento de etanol a partir da glicose tenha se mostrado satisfatório, as células apresentaram metabolismo respiratório diante da xilose e da celobiose. Considerando a restrição de nitrogênio dos meios utilizados, os dados obtidos sugerem que as leveduras analisadas apresentam potencial para contribuir com a otimização da produção de etanol de segunda geração.
\end{abstract}

\section{INTRODUÇÃO}

O Brasil é o segundo maior produtor mundial de etanol. O etanol brasileiro é atualmente produzido a partir da fermentação do caldo e/ou do melaço da cana-de-açúcar, substratos ricos em sacarose. Entretanto, como subproduto dessa produção são gerados cerca de 150 milhões de toneladas de bagaço de cana-de-açúcar por ano (Silva et al., 2014). Esse resíduo é rico em açúcares fermentescíveis que não são utilizados na produção do etanol de primeira geração, mas que podem vir a ser usados na produção de etanol de segunda geração (etanol $2 \mathrm{G}$ ou etanol lignocelulósico). Com isso, pode-se aumentar em até $50 \%$ a produção de etanol sem aumentar a área de cana plantada (Zanin et al., 2010; Stambuk et al., 2008; Soccol et al., 2010).

Para que ocorra esse processo, no entanto, é necessário que a celulose e a hemicelulose presentes nessa biomassa sejam hidrolisadas, liberando assim seus mono e dissacarídeos para a subsequente fermentação. A partir da quebra da celulose, obtêm-se principalmente glicose e 
celobiose, enquanto a hidrólise da porção hemicelulose resulta especialmente no monossacarídeo xilose (Beg et al., 2001; Collins et al., 2004; Zhang et al., 2012).

Contudo, a levedura Saccharomyces cerevisiae, embora seja ainda considerada a mais bem adaptada às dornas de fermentação nas usinas sucroalcooleiras, é incapaz de metabolizar alguns dos principais carboidratos oriundos da fase de hidrólise da biomassa lignocelulósica, entre eles a celobiose e a xilose (Stambuk et al., 2008; Lee et al., 2013). Em razão disso, pesquisas vêm sendo realizadas com o objetivo de encontrar enzimas que possam ser heterologamente expressas em $S$. cerevisiae e/ou de encontrar novas espécies de leveduras que tolerem às condições de estresse impostas às células durante a produção de etanol (Reis $e t$ al., 2014; Wang et al., 2016). Nesse contexto, o presente trabalho se propôs a analisar leveduras isoladas de bagaço e palha de cana-de-açúcar, frente a diferentes fontes de carbono, com vistas a contribuir para a otimização da produção de etanol $2 \mathrm{G}$.

\section{METODOLOGIA}

\subsection{Isolamento das Leveduras e Determinação do Crescimento Celular}

As leveduras foram isoladas a partir de amostras de bagaço e palha de cana-de-açúcar em decomposição, obtidas a partir da produção das áreas experimentais do Campus Chapecó da Universidade Federal da Fronteira Sul (UFFS). O isolamento seguiu o protocolo descrito por Cadete et al. (2009). As amostras foram coletadas em tubos Falcon de $50 \mathrm{~mL}$ estéreis. De cada amostra, foi inoculada $1 \mathrm{~g}$ em $20 \mathrm{~mL}$ de meio sintético mínimo, contendo $0,67 \%$ de base nitrogenada, $0,02 \%$ de cloranfenicol e $1 \%$ de xilose. Foram preparados quatro frascos erlenmeyer e incubados a $25^{\circ} \mathrm{C}$ por 3-10 dias, sob agitação periódica de $145 \mathrm{rpm}$. Quando detectou-se crescimento celular, uma alçada de células foi estriada por esgotamento em placas de Petri, contendo os mesmos meios supracitados, além da adição de $2 \%$ de ágar. As placas foram incubadas a uma temperatura de $28^{\circ} \mathrm{C}$ e as leveduras foram isoladas através da morfologia de colônias.

Para a realização dos crescimentos celulares, as leveduras foram inicialmente précrescidas por $48 \mathrm{~h}$ em $10 \mathrm{~mL}$ de meio rico, contendo $1 \%$ de extrato de levedura, $2 \%$ de peptona e $2 \%$ de glicose. Essas células pré-crescidas foram em seguida inoculadas (1/100 do volume final) em frascos erlenmeyers com meio mínimo, contendo 0,67\% de base nitrogenada e $2 \%$ de glicose, xilose ou celobiose como fontes de carbono. Todos os meios foram ajustados em $\mathrm{pH} 5,0$. Os frascos foram incubados a $25^{\circ} \mathrm{C}$ sob agitação periódica de 145 rpm. Nos tempos estipulados, amostras foram coletadas dos cultivos e utilizadas para determinação do crescimento celular em espectrofotômetro, por absorbância a $570 \mathrm{~nm}$ ( $\left.\mathrm{DO}_{570 \mathrm{~nm}}\right)$, e para a quantificação de açúcares e de etanol, conforme descrito abaixo.

\subsection{Determinação do Consumo de Açúcares e da Produção de Etanol}

Durante os crescimentos celulares, amostras foram retiradas dos meios de cultivo, centrifugadas e seus sobrenadantes temporariamente armazenados a $-20^{\circ} \mathrm{C}$ antes da quantificação de açúcares e etanol.

As dosagens de açúcares redutores foram realizadas conforme o método de DNS em microplacas descrito por Santos et al. (2017). A reação aconteceu em microplacas de 96 
poços (fundo chato). Em cada poço foram adicionados $25 \mu \mathrm{L}$ de amostra (diluídas 10 ou 5 vezes com água destilada, para que ficassem dentro da curva de calibração) e $25 \mu \mathrm{L}$ do reativo DNS. A microplaca foi selada com filme plástico e levada a banho fervente por 5 min. Em seguida, a microplaca foi resfriada no gelo e adicionou-se $330 \mu \mathrm{L}$ de água destilada, sendo lida logo após em uma leitora de microplacas da marca BIOTEK, modelo ELx 800 com feixe de luz a $490 \mathrm{~nm}$. Para cada açúcar analisado, em cada placa, foi montada uma curva padrão com as concentrações de $0,2,0,4,0,8,1,6$ e $2,0 \mathrm{~g} / \mathrm{L}$.

As dosagens de etanol foram feitas por Cromatografia Líquida de Alta Eficiência (HPLC), em cromatógrafo da marca Shimadzu, modelo LC-20, com detector RID-10A, coluna NST 18 (C18), com tempo de retenção de 4min40s, usando como fase móvel água ultrapura acidificada com $\mathrm{H}_{3} \mathrm{PO}_{4} 0,1 \%$ a uma temperatura de $40^{\circ} \mathrm{C}$.

\section{RESULTADOS E DISCUSSÃO}

Com o propósito de selecionar leveduras com potencial para aumentar a viabilidade da produção de etanol de segunda geração, foram isoladas 16 linhagens de leveduras de bagaço e palha de cana-de-açúcar em decomposição. Essas cepas foram nomeadas seguindo a numeração da coleção de cepas do grupo de pesquisa. Entre as leveduras isoladas, 4 cepas foram aleatoriamente escolhidas para a avaliação dos seus perfis de crescimento celular, consumo de açúcares e produção de etanol em meios contendo alternadamente glicose, xilose ou celobiose como fontes de carbono (conforme descrito na metodologia).

Os dados obtidos demonstram que as quatro linhagens analisadas (CHAP-111, CHAP116, CHAP-119 e CHAP-125) foram capazes de crescer assimilando as três fontes de carbono testadas (vide Figuras 1, 2 e 3). Quando comparada aos meios com glicose, a produção de biomassa celular mostrou-se ligeiramente superior em xilose e celobiose para as quatro leveduras analisadas, o que se deve ao fato de essas linhagens terem realizado metabolismo respiratório em vez do fermentativo diante desses dois últimos carboidratos.

Figura 1 - Perfis de crescimento celular (A), consumo de açúcar (B) e produção de etanol (C) das linhagens CHAP-111, CHAP-116, CHAP-119 e CHAP-125 em meio mínimo contendo glicose como fonte de carbono.

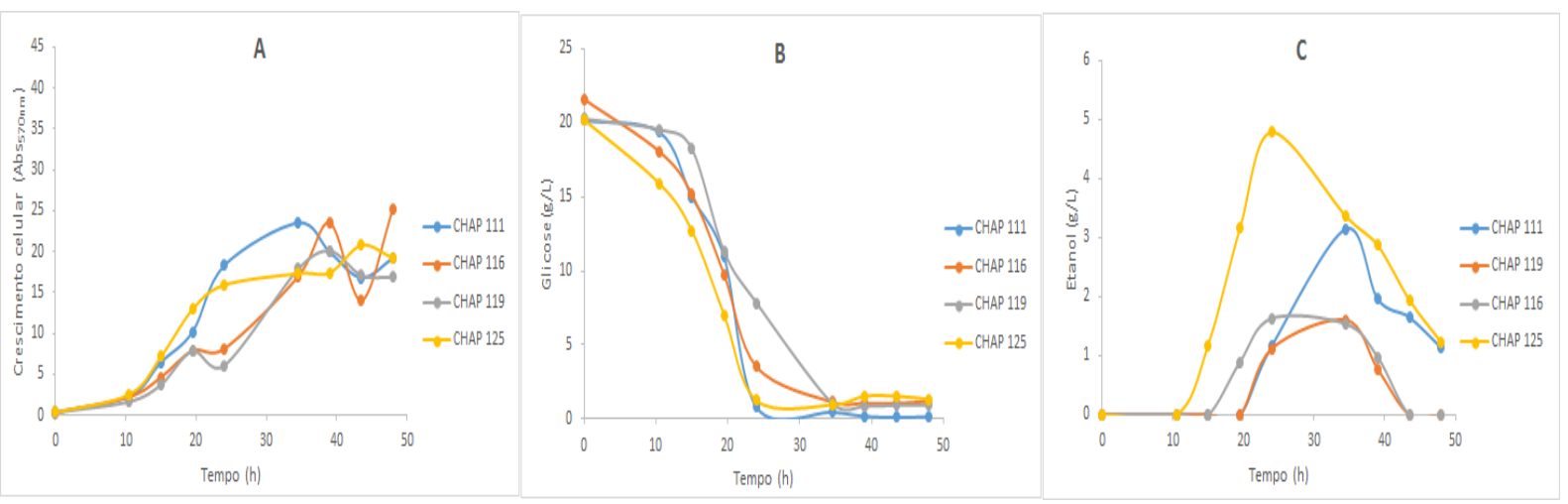


Figura 2 - Perfis de crescimento celular (A), consumo de açúcar (B) e produção de etanol (C) das linhagens CHAP-111, CHAP-116, CHAP-119 e CHAP-125 em meio mínimo contendo xilose como fonte de carbono.

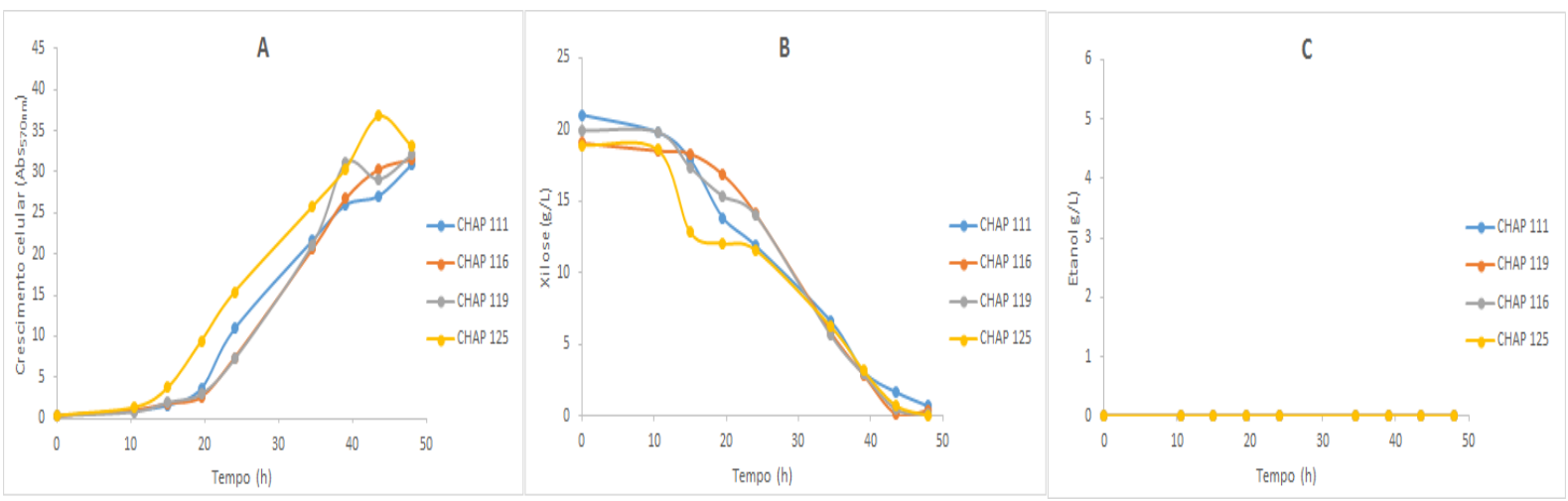

Figura 3 - Perfis de crescimento celular (A), consumo de açúcar (B) e produção de etanol (C) das linhagens CHAP-111, CHAP-116, CHAP-119 e CHAP-125 em meio mínimo contendo celobiose como fonte de carbono.

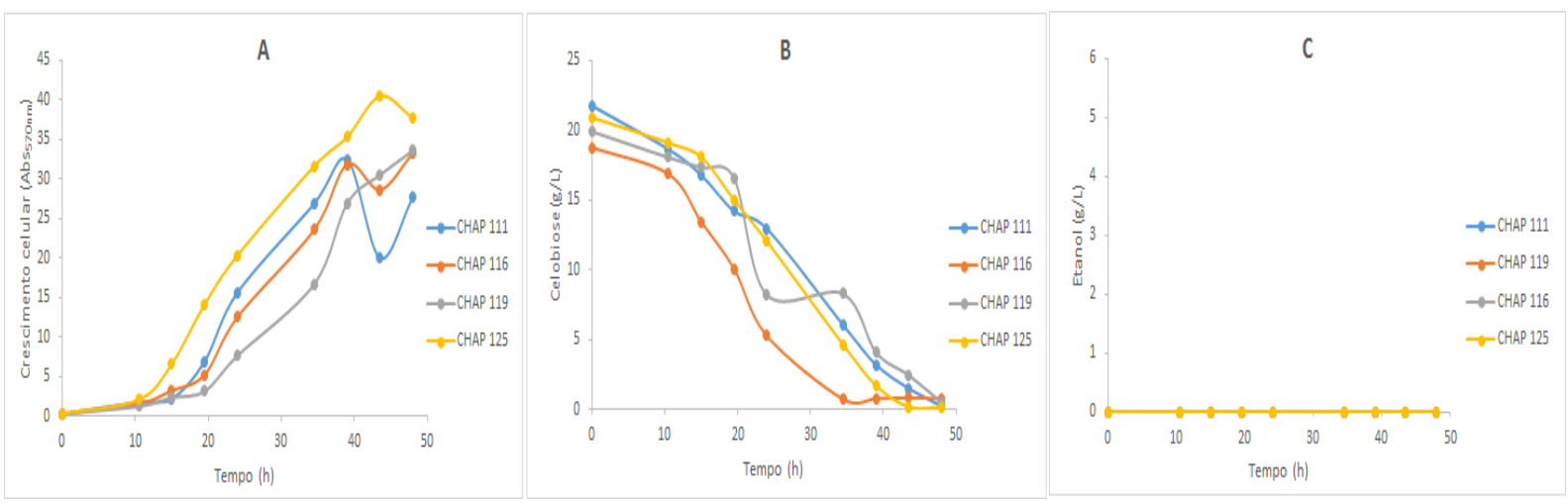

O consumo da glicose, nas quatro linhagens, aconteceu de forma mais acelerada em comparação com os outros dois carboidratos (Figuras 1-B, 2-B e 3-B), sendo que em menos de $25 \mathrm{~h}$ as cepas CHAP-111 e CHAP-125 já haviam consumido toda essa hexose, enquanto que o consumo total de xilose e celobiose só ocorreu após 35-40 h de incubação. Esses resultados corroboram dados presentes na literatura, que demonstram que as leveduras assimilam mais rapidamente a glicose em comparação a outros carboidratos (Santos et al., 2011). Ademais, muito provavelmente foi em razão desse consumo mais rápido que as linhagens testadas fermentaram a glicose mas não a xilose e a celobiose (Figuras 1-C, 2-C e 3-C); sabe-se que quando açúcares são absorvidos mais vagarosamente pelas células, seu metabolismo é essencialmente respiratório (Duval et al., 2010).

Hande et al. (2013) demonstraram que a fonte de nitrogênio é importante para o rendimento fermentativo das leveduras. Em seu trabalho, esses autores apontam que o rendimento de etanol em meios contendo amônia como fonte de nitrogênio (como foram os 
meios utilizados no presente trabalho) é apenas pouco mais da metade do rendimento observado em meios cuja fonte de nitrogênio provenha de extrato de levedura e peptona. Assim sendo, considerando o meio utilizado e o fato de serem leveduras selvagens, pode-se assumir um rendimento de etanol satisfatório a partir de glicose, especialmente para a linhagem CHAP-125, que produziu 4,79 g/L de etanol, o que representa um rendimento $\left(Y_{\mathrm{e} / \mathrm{s}}\right)$ de $0,24 \mathrm{~g} \cdot \mathrm{g}^{-1}$. Além disso, é possível que em meio rico essas mesmas linhagens viessem também a fermentar xilose e celobiose. Desse modo, seriam interessantes novos trabalhos para avaliar o rendimento fermentativo dessas leveduras em meios com diferentes fontes de nitrogênio.

\section{CONCLUSÃO}

Embora as linhagens analisadas, frente a xilose e celobiose, tenham apresentado metabolismo respiratório em vez de fermentativo, haja vista a restrita disponibilidade de nitrogênio em meios mínimos, as leveduras aqui testadas foram capazes de assimilar esses dois carboidratos durante o tempo de cultivo e foram capazes de fermentar a glicose. Tem-se, portanto, um indicativo do potencial das leveduras avaliadas em contribuir com a otimização da produção de etanol de segunda geração, seja como microrganismos fermentadores ou como fontes de genes que codificam as enzimas necessárias para o metabolismo de xilose e celobiose.

\section{REFERÊNCIAS}

BEG, Q. K.; KAPOOR, M.; MAHAJAN, L.; HOONDAL, G. S. Microbial xylanases and their industrial applications: a review. Appl Microbiol Biotechnol., v. 56, p. 326-338, 2001 .

CADETE, R. M.; SANTOS, R. O.; MELO, M. A.; MOURO, A.; GONÇALVES, D. L.; STAMBUK, B. U.; GOMES, F. C. O.; LACHANCE, M. A.; ROSA, C. A. Spathaspora arborariae sp. nov., a D-xylose-fermenting yeast species isolated from rotting wood in Brazil. FEMS Yeast Res., v. 9, p. 1338-1342, 2009.

COLLINS, T.; GERDAY, C.; FELLER, G. Xylanases, xylanase families and extremophilic xilanases. FEMS Microbiol Rev., v. 29, p. 3-23, 2004.

DUVAL, E. H.; ALVES, S. L. JR.; DUNN, B.; SHERlOCK, G.; STAMBUK, B. U. Microarray karyotyping of maltose-fermenting Saccharomyces yeasts with differing maltotriose utilization profiles reveals copy number variation in genes involved in maltose and maltotriose utilization. J. Appl. Microbiol., v. 109, p. 289-259, 2010.

HANDE, A.; MAHAJAN, S.; PRABHUNE, A. Evaluation of ethanol production by a new isolate of yeast during fermentation in synthetic medium and sugarcane bagasse hemicellulosic hydrolysate. Ann. Microbiol., v. 63, p 63-70, 2013.

LEE, W. H.; Nan, H.; Kim, H. J.; Jin, Y. S. Simultaneous saccharification and fermentation by engineered Saccharomyces cerevisiae without supplementing extracellular Bglucosidase. J. Biotechnol., v. 167, p. 316-322, 2013. 
REIS, A. L. S.; DE SOUZA, R. F. R.; TORRES, R. R. N. B.; LEITE, F. C. B.; PAIVA, P. M. G.; VIDAL, E. E.; MORAIS, M. A. Jr. Oxygen-limited cellobiose fermentation and the characterization of the cellobiase of an industrial Dekkera/Brettanomyces bruxellensis strain. SpringerPlus, v. 3, p. 38, 2014.

SANTOS, A. A.; DEOTIR, J. R.; MÜLLER, G.; DÁRIO, M. G.; STAMBUK, B. U.; ALVES S. L. Jr. Microwell plate-based method for the determination of reducing sugars with the DNS reagent. Braz. J. Food Technol., v. 20, p. e2015113, 2017.

SANTOS, R. O.; CADETE, R. M.; BADOTTI, F.; MOURO, A.; WALHEIM, D. O.; GOMES, F. C. O.; LACHANCE, M. A.; ROSA, C. A. Candida queiroziae sp. nov., a cellobiose-fermenting yeast species isolated from rotting wood in Atlantic Rain Forest. Antonie Van Leeuwenhoek, v. 99, p. 635-642, 2011.

SILVA, L. F.; TACIRO, M. K.; RAICHER, G.; PICOLLI, R. A.; MENDONÇA, T. T.; LOPES, M. S.; GOMEZ, J. G. Perspectives on the production of polyhydroxyalkanoates in biorefineries associated with the production of sugar and ethanol. Int. J. Biol. Macromol., v. 71, p. 2-7, 2014.

SOCCOL, C. R.; VANDENBERGHE, L. P.; MEDEIROS, A. B.; KARP, S. G.; BUCKERIDGE, M.; RAMOS, L. P.; PITARELO, A. P.; FERREIRA-LEITÃO, V.; GOTTSCHALK, L. M.; FERRARA, M. A.; DA SILVA BOM, E. P.; DE MORAES, L. M.; ARAÚJO, J. A.; TORRES, F. A. Bioethanol from lignocelluloses: Status and perspectives in Brazil. Bioresource Technology, v. 101, p. 4820-4825, 2010.

STAMBUK, B. U.; ELEUTHERIO, E. A.; FLOREZ-PARDO, L. M.; SOUTO-MAIOR, A.; BON, E. S. Brazilian potential for biomass ethanol: challenge of using hexose and pentose cofermenting yeast strains. J. Sci. Ind. Res., v. 67, p. 918-926, 2008.

WANG. X.; LIU, Z.L.; WEBER, S. A.; ZHANG, X. Two New Native $\beta$-Glucosidases from Clavispora NRRL Y-50464 Confer Its Dual Function as Cellobiose Fermenting Ethanologenic Yeast. PLoS One, v. 11, p. e0151293, 2016.

ZANIN. G. M.; SANTANA C. C.; BOM, E. P.; GIORDANO, R. C.; DE MORAES, F. F.; ANDRIETTA, S. R.; DE CARVALHO NETO, C. C. Brazilian Bioethanol Program. Appl. Biochem. Biotechnol., v. 84-86, p. 1147-1161, 2000.

ZHANG, Z.; DONALDSON, A. A.; MA, X. Advancements and future directions in enzyme technology for biomass conversion. Biotechnol. Adv., v. 30, p. 913-919, 2012. 